\title{
Computer-Supported Cooperative Work and Groupware: An Introduction to the Special Edition
}

\author{
Saul Greenberg \\ Department of Computer Science, \\ University of Calgary \\ Calgary, Alberta, Canada T2N 1N4 \\ phone: $\quad+14032206087$ \\ saul@cpsc.ucalgary.ca
}

Cite as:

Greenberg, S. (1991). Computer supported cooperative work and groupware: An introduction to the special edition. International Journal of Man Machine Studies, 34(2), pp. 133-143, February. Also describes 34(3).

\section{Abstract}

This two-edition series on computer supported cooperative work and groupware contains sixteen original articles, selected from over forty submissions. As the papers were chosen on individual technical merit, the collection does not introduce all aspects of CSCW and groupware. Still, the new reader should gain some insight of what this field is about, while the active CSCW researcher and groupware implementor will be informed of several exciting new findings.

\section{Introduction}

Although computers are now familiar tools used by people to pursue their own individual tasks, they have not generally been exploited to assist people working together. Off-the-shelf applications in typical use are for the most part "single-user" systems. Word processors, spread sheets, idea outliners, drawing tools, and slide preparation packages (to name a few) are all built to support one person's work, with little regard to the fact that people often work together. Even the scientific study of human-computer interaction has emphasised exploring issues involved when a single user interacts with a computer. It is only recently that attention has turning to multi-user systems, through computer supported cooperative work and groupware.

Groupware is software that supports and augments group work. It is a technicallyoriented label meant to differentiate "group-oriented" products, explicitly designed to assist groups of people working together, from "single-user" products that help people pursue only their isolated tasks. The more familiar groupware examples include electronic mail, bulletin boards, asynchronous conferencing, group schedulers, group decision support systems, collaborative authoring tools, screensharing software, computer equivalents to whiteboards, video conferencing, and so on (eg Johansen, 1988). 
In contrast, computer-supported cooperative work (CSCW) is the scientific discipline that motivates and validates groupware design. It is the study and theory of how people work together, and how the computer and related technologies affect group behaviour. CSCW is an umbrella collecting researchers from a variety of specializations-Computer Science, Cognitive Science, Psychology, Sociology, Anthropology, Ethnography, Management, Management Information Systems--each contributing a different perspective and methodology for acquiring knowledge of groups and for suggesting how the group's work could be supported.

Yet CSCW is not particularly well-defined, a consequence of its youth and its multidisciplinary nature. A visible symptom of this uncertainty is the varying and at times controversial mix of papers accepted at CSCW conferences, with attendees often debating why certain topics were considered relevant by the programming committee. Nor is there consensus on what applications should be considered "groupware". Grudin (1991) lists examples of how people have drawn the line between groupware and its substrate, with some believing it starts at a very low technical level (eg a Network File Server), and others stating that it begins somewhere above electronic mail! Even the "computer supported cooperative work" label has come under fire for a variety of reasons (eg Bannon and Schmidt, 1989; Grudin, 1991). For example:

- computer-technologies other than computers (such as video) are considered within the CSCW domain;

- supported-while support may be offered to the group as a whole, activities of particular individuals may be disrupted;

- cooperative-the social process can include not only cooperation, but aggression, competition, loose coordination, and tight collaboration;

- work-casual and social interaction must be supported as well, for they are considered a vital precursor to the work process (Kraut, Egido, and Galegher, 1988).

Essays exploring and arguing the foundations of CSCW has been forwarded by Bannon et al (1988), Bannon and Schmidt (1989), Greif (1988), and Grudin (1991). Rather than split semantic hairs of what CSCW is or should be, Bannon et al's original pragmatism is adopted here.

"We believe that for the moment the name CSCW simply serves as a useful forum for a variety of researchers with different backgrounds and techniques to discuss their work, and allows for the cross-fertilization of ideas, for the fostering of multi-disciplinary perspectives on the field that is essential if we are to produce applications that really are useful."

(Bannon et al., 1988)

\section{Contents of the Special Edition}

This two-edition series on computer supported cooperative work and groupware contains sixteen original articles, selected from over forty submissions. As the papers were chosen on individual technical merit, the collection does not introduce all aspects of CSCW and groupware. Still, the new reader should gain some insight 
of what this field is about, while the active CSCW researcher and groupware implementor will be informed of several exciting new findings and perspectives.

In order to establish a sense of context for the reader, this section introduces and loosley categorizes the collected papers.

\subsection{Methodology}

Traditional experimental methodologies employed to study human-computer interactions are often inadequate for studying group situations. When real group dynamics are awkward to replicate in a laboratory, researchers must resort to observing behaviour in the field. Studies are characterized by many variables and uncontrollable factors, and often require observations over lengthy time spans. New methodologies are essential.

Several of the articles interspersed in the special edition serve a purpose beyond their specific research findings, for they also introduce methodologies that may be novel to the reader. Both Lea's and Weedman's articles, for example, illustrate how conventional experimental psychology can still be applied to study fine details of group behaviour. In contrast, Tang's use of "video as data" (Mackay and Tatar, 1989 ) is an example of a relatively new way of collecting data that helps establish insight into group behaviour under less controlled conditions. His article also provides an example of an ethnographic study, particularly in how complex group activity can be categorized, counted, and interpreted. Nardi and Miller also offer an ethnographic study, in this case using extensive interviewing of subjects along with an analysis of the artifacts produced by the group. Tatar, Foster and Bobrow show how even brief usability studies-simple observations of "real" users (not developers) interacting through a system-can highlight serious problems that may be otherwise overlooked. They also demonstrate the value of using models and theories from non computer-based fields (in this case conversational analysis and psycho-linguistics) to explain the group's reaction to the particular groupware system. Olson and Bly reveal how an objective outside observer can be brought in to examine a long-term work process.

Although the methods employed by the above researchers are far from exhaustive, they do sample the diverse methodologies involved in CSCW research.

\subsection{Studying groups without groupware.}

Knowing how people work together without groupware is an essential first step for designing appropriate software. The first two papers in this series take this approach. Tang analyses key aspects of shared activity around a paper sketchpad by studying video transcripts of small group design sessions. The result is a set of specific recommendations for the design of tools to support shared workspace activity, results which have now been taken up by several prototype video and electronic workspaces (for examples see Bly and Minneman 1990; Greenberg and Bohnet 1990; Ishii 1990; Tang and Minneman, 1990).

Nardi and Miller's study is on spreadsheets, long considered a good example of a 
well designed "single user" application. Much to their surprise, they observed that spreadsheet co-development was the rule, not the exception. They saw a high degree of cooperation in sharing program expertise, transferring domain knowledge, debugging, training, and face to face work in meetings. The general implication is that cooperative work happens all the time, in spite of the inherent limitations of the software.

\subsection{Studying groups with groupware}

When groupware is available, its effect on the group can be evaluated and further implications for design developed. Tatar, Foster and Bobrow, for example, review Cognoter, a multi-user idea organizer that was part of Xerox PARC's original CoLab suite (Stefik, Foster, Bobrow et al, 1987). They noticed that its users encountered unexpected communication breakdowns, which they attribute to the Cognoter's incorrect model of conversation implicit in its design. By using a more appropriate model of conversation, they were not only able to pin-point the previous design decisions that had contributed to the difficulties users had, but they were able to amend the design as well.

Media Space is a video, audio, and computing network established to support distributed research across two quite distant laboratories. Olson and Bly observed the laboratories' usage evolution of Media Space over two years. The resulting article reports on the requirements for distributed research, and indicates where the technology both succeeded and failed to support various aspects of the collaborations.

Borenstein and Thyberg's article describes the Messages user interface to the Andrew Message System (AMS), a powerful multi-media mail and bulletin board program. The authors walk the reader through the original design assumptions of Messages and detail its features. What makes Messages interesting is that it is a real system, with several thousand users. The continuous user involvement meant that faults quickly became evident, motivating rapid redesign. As an example, they step us through three iterations of the Adviser, a Messages subsystem designed to allow experts to provide advice to queries from AMS users.

\subsection{Computer-mediated communications and group decision support systems}

Computer support for meetings is becoming an increasingly common way to assist the group decision-making process. In face to face settings, we are not only seeing specially-built meeting rooms (eg Mantei, 1988), but also cheap LED projectors that can display a computer screen's contents on a large screen. In asynchronous environments, electronic mail and computer conferencing enable on-going discussions between time and distance-separated people.

But what makes good electronic meeting support? Valacich, Dennis, and Nunamaker Jr have worked with the University of Arizona's GroupSystems face to face meeting room for several years. They highlight the theoretical assumptions behind the system's design and describe GroupSystem's workings. Of particular importance is 
that GroupSystems has been well-studied; fifteen experimental and field studies are summarize and contrasted here. The authors then provide recommendations for developers of electronic meeting rooms based upon the lessons learnt.

Technology changes the way people within a group behave. Lea and Spears discuss how computer-mediated communication affects deindividuation, the anonymity and loss of identity that occurs when people are submerged in a group. If deindividuation does exist, we would expect the social norms and constraints of people's behaviour to be weakened, which would have serious consequences on how decisions made by the group should be interpreted. The authors question past findings on how electronic communication changes the group's psychological states, and then present their own study and alternate view of the role of deindividuation.

What is computer-mediated communication used for? Some systems are based upon the assumption that communication is related to a specific task or action which can be captured and formalized (eg the Coordinator, Winograd, 1988). Weedman noticed that typical asynchronous computer communication also has a large non-task component used for such things as social exchange, expressing frustrations, and so on. She argues that since variety and vigour of communication is important to successful collaboration, the underlying technology should be flexible enough to support informal as well as formal talk.

\subsection{Novel \& Innovative Groupware Technologies}

CSCW exhibits the same push and pull between theory and creative technologies that exists in traditional human-computer interaction. Four of the works in this series demonstrate innovations that may alter our perspectives on groupware fundamentals.

Recent developments in interactive Virtual Environments has sparked interest in spatially-located three-dimensional sound. Cohen and Ludwig describe an audio management system called audio windows that integrates spatial sound, audio emphasis, and gestural input recognition. While this exciting use of computercontrolled sound can be applied to any aspect of the human computer interface, the article suggests new enhancements this technology can bring to tele-conferencing.

A large part of a group process is information sharing. While networked computers usually allow people within an institution to share information across common data files, networks are rarely available for loosley-coupled social groups. Witten, Thimbleby, Coulouris and Greenberg describe Liveware, a socially productive benign virus used to spread information across intermittently connected people and groups. Unlike conventional wired networks, Liveware is cheap, does not require a technical infrastructure, and is intrinsically intertwined with social convention of "casual" information sharing by mobile and flexible work groups.

Hypertext developers now recognize that hypertext documents will be used and updated by large groups of people. Rein and Ellis take the next logical step by combining both real-time with asynchronous hypertext manipulation in their rIBIS system. An rIBIS session is a distributed meeting where participants can be in a 
"tightly-coupled" or "loosley-coupled" mode. In the first, tightly-coupled members all see the same thing, and take turns controlling and manipulating the hypertext display. In the second, a person works semi-privately by editing a portion of the hypertext-only large-grained changes are broadcast to other members. The result is a system valuable not only for storing information, but also for allowing people to actively capture and structure critical aspects of a meeting process.

Cook, Birch, Murphy, and Woolsey are "strict constructionists": implementors interested in the underlying architectures and technologies supporting groupware. They create a model of a groupware system, and use it to explore, implement, and evaluate a system architecture. The paper reveals what constraints the developers chose to work under, how they actually built the system, and how they judged what worked and what did not. The paper also highlights a serious problem currently facing all groupware developers; the lack of an adequate toolkit for constructing applications.

\subsection{Removing Rigidity from Groupware}

Peter and Trudy Johnson-Lenz suggest that today's approach to groupware is mechanistic, ie based upon some social theory of human interaction or taskoriented approach that can be modelled by a machine. At the other extreme (also supported by Dykstra) is groupware as context, based on the social theory that human systems are self-organizing and arise out of the unrestricted interaction of autonomous individuals. Dykstra's article pursues this latter view. She argues that while systems should nourish conversation and stimulate interaction amongst group participants, they should not directly regulate the actual meeting process. Instead, the technology should be supple enough to allow the group itself to define its own (perhaps changing) conventions, structures, and constraints. Several iterations of the Amsterdam Conversation Environment, a system supporting groupware as context, are described.

The Johnson-Lenz's delightful article takes the middle ground. Instead of eschewing system support for process, they describe how the computer can perhaps capture the emergence of the group's process, and then create appropriate forms for supporting it. They consider their approach "post-mechanistic" as the model of group behaviour is not rigidly codified into the system but evolves with the group. Their implementation is particularly intriguing not only for technical reasons, but because the subject domain is "self-help", a far cry from the usual businessoriented applications emphasised by developers.

\subsection{Participatory design}

Unlike conventional interface design approaches that consider user involvement a sequence of intermittent consultations, participatory design has the design team comprised of developers and eventual system users. Both actively and continuously participate in planning and decision making in order to build a system that truly matches what the workers need. Participatory design is now touted as a critical requirement for successful groupware design, on the premise that the resulting product will be more usable by all team members. 
While participatory design has generally succeeded for software development targetted to producing systems specific to an in-house organizational context, it has not really been applied to product development organizations that design massproduced off-the-shelf products. Grudin suggests that in spite of the benefits participatory design may offer for improving a system interface (particularly for groupware systems), there are several serious obstacles to user involvement. Most stem from organizational structures and development practices that arose prior to the current market for interactive systems. Recognizing these obstacles is, of course, the first step in overcoming them.

Given an environment conducive to participatory design, how does one go about doing it? Bodker and Gronbaek describe one method called cooperative prototyping. These involve sessions where users experience the future use situation, and then participate with designers in modifying the prototypes when usage breakdowns require it. Their article is especially valuable as it provides a theoretical framework, a practical guide for managing cooperative prototyping sessions, and an example of how cooperative prototyping develops in a real situation.

\section{Further readings and sources}

Due to the youth and diversity of CSCW, there are only a handful of specialized books available. Most of the literature is scattered amongst many journals, proceedings of conferences and workshops, and technical reports. This section is a resource guide for readers interested in finding relevant literature in CSCW and groupware.

Books. Perhaps the best overview of the CSCW discipline is provided by Irene Greif (Greif, 1988). Her collected readings span from the earliest visions of CSCW to present day theory and practice. On the groupware front, Johansen provides a very readable layman's book detailing current approaches and applications of groupware to business teams (Johansen, 1988). Two other recent books also collect CSCW articles. Both cover social and technological support for work group collaborations (Galegher, Kraut and Egido, 1990; Olson, 1989).

Journals. There are no dedicated journals for CSCW. Still, the ones listed below do publish occasional papers of interest.

ACM Transactions on Office Information Systems has had several special editions on CSCW. These tend to re-publish selected (and slightly revised) papers previously presented at the ACM-sponsored CSCW conferences (see below). In particular, see Volumes 5(2) 1987, 6(3) 1988 and 6(4) 1988. A forthcoming edition will feature several articles from the CSCW'90 conference.

The International Journal of Man Machine Studies has formalized its interest in CSCW in its re-organization of the editorial board into topic areas, one being CSCW. This two-volume special edition is an example of the journal's commitment to providing a publication platform to CSCW research.

ACM's SIGCHI Bulletin and SIGOIS Bulletin occasionally contain relevant articles and 
summaries of conferences and workshops. The December 1988 issue of Byte had a special section devoted to CSCW papers, and the odd high-quality article has appeared in Communications of the ACM and IEEE Computer. Other mainstream human-computer interface journals should have occasional articles on CSCW. These include Office: Technology and People; Interacting with Computers; Human Computer Interaction; and Behaviour and Information Technology.

Conferences. The major conference for CSCW is the bi-annual ACM-sponsored "Conference on Computer-Supported Cooperative Work." The first conference was held in 1986 (Austin, Texas). Although its proceedings are no longer in publication, many of the articles have been reprinted in revised form in the books and journals mentioned above. Proceedings of the 1988 (Portland, Oregon) and the 1990 (Los Angeles, California) conference are available from ACM Press (ACM Order Department, PO Box 64145, Baltimore, MD, USA 21264). These proceedings are of excellent quality, with collected papers covering most contemporary work.

The "European Community Conference on Computer Supported Cooperative Work is the European counterpart to the ACM conference. The first was held on September 13-15 in Gatwick, London, UK, with a second scheduled for fall of 1991 in Amsterdam, The Netherlands. Proceedings are available from the Computer Sciences Company, Computer Sciences House, Brunel Way, Slough, United Kingdom SL1 1XL.

Another recent conference was the "IFIP WG8.4 Conference on Multi-User Interfaces and Applications". Session titles included: multi-user interface design; cooperative development of software; shared environments; desktop conferencing and multiuser editing; messaging; experiences with multi-user applications; and coordination (Gibbs and Verrijn-Stuart, 1990).

The University of Guelph sponsors the "Symposium on Computer Conferencing". While earlier conferences tended to centre around distance education and asynchronous conferencing, the later ones have broader coverage (University Of Guelph, 1987 and 1990). ACM's "SIGCHI Conference on Computer-Human Interaction" and "SIGOIS Conference on Office Information Systems" normally have special sessions, panels or papers on CSCW.

For those wishing more detailed references, an annotated bibliography of Computer Supported Cooperative Work is available by writing the author at the address at the front of this article (Greenberg, 1991).

Acknowledgements. I am indebted to the Alberta Research Council who provided me with the resources and release time required to manage and edit this special edition.

\section{References}

1. Bannon, L., Bjorn-Andersen, N. and Due-Thomsen, B. (1988) "Computer support for cooperative work: An appraisal and critique." In Eurinfo '88. Information Systems for Organizational Effectiveness. Amsterdam, Bullinger, 
H. J., North-Holland.

2. Bannon, L. J. and Schmidt, K. (1989) "CSCW: Four characters in search of a context." In Proceedings of the European Community Conference on Computer Supported Work (EC-CSCW), 358-372, London, September.

3. Bly, S. A. and Minneman, S. L. (1990) "Commune: A shared drawing surface." In Proceedings of the Conference on Office Information Systems, 184-192, Boston, April 25-27.

4. Galegher, J., Kraut, R. and Egido, C. (ed.) (1990) Intellectual teamwork: Social and technological foundations of group work. Hillsdale, NJ, Lawrence Erlbaum Associates.

5. Gibbs, S. and Verrijn-Stuart (ed.) (1990) Proceedings of IFIP WG8.4 Conference on Multi-User Interfaces and Applications (Crete). Amsterdam, North Holland.

6. Greenberg, S. (1991) "An annotated bibliography of computer supported cooperative work: Revision 2." Research Report, Department of Computer Science, University of Calgary, Calgary, Alberta, Canada.

7. Greenberg, S. and Bohnet, R. (1990) "GroupSketch: A multi-user sketchpad for geographically-distributed small groups." Reseach report 90/414/38, Department of Computer Science, University of Calgary,Calgary, Alberta, Canada, November.

8. Greif, I. (ed.) (1988) Computer-supported cooperative work: A book of readings. San Mateo, California, Morgan Kaufmann Publishers Inc.

9. Grudin, J. (1991) "CSCW: The convergence of two disciplines." In ACM SIGCHI Conference on Human Factors in Computing Systems, New Orleans, April, ACM Press.

10. Ishii, H. (1990) "TeamWorkStation: Towards a seamless shared space." In Proceedings of the Conference on Computer-Supported Cooperative Work, 1326, Los Angeles, California, October 7-10, ACM Press.

Johansen, R. (1988) Groupware: Computer Support for Business Teams. New York, The Free Press, Macmillan Inc.

11. Kraut, R., Egido, C. and Galegher, J. (1988) "Patterns of contact and communication in scientific collaboration." In Proceedings of the Conference on Computer-Supported Cooperative Work, 1-12, Portland, Oregon, September 26-28, ACM Press.

12. Mackay, W. E. and Tatar, D. G. (1989) "Special issue on video as a research and design tool." SIGCHI Bulletin, 21(2), October.

13. Mantei, M. (1988) "Capturing the Capture concepts: A case study in the design of computer-supported meeting environments." In Proceedings of the Conference on Computer-Supported Cooperative Work, 257-270, Portland, Oregon, September 26-28, ACM Press.

14. Olson, M. H. (ed.) (1989) Technological support for work group collaboration. Hillsdale, New Jersey, Lawrence Erlbaum Associates.

15. Stefik, M., Foster, G., Bobrow, D., Kahn, K., Lanning, S. and Suchman, L. (1987) "Beyond the chalkboard: Computer support for collaboration and problem solving in meetings." Communications of the ACM, 30(1), 32-47, Reprinted in Greif, 1988.

16. Tang, J. C. and Minneman, S. L. (1990) "Videodraw: A video interface for collaborative drawing." In ACM SIGCHI Conference on Human Factors in Computing Systems, 313-320, Seattle Washington, April 1-5, ACM Press. 
17. University Of Guelph (1987) The second Guelph symposium on computer conferencing. Guelph, Ontario, Canada, University of Guelph, June 1-4.

18. University Of Guelph (1990) The third Guelph symposium on computer mediated communication. Guelph, Ontario, Canada, University of Guelph, Continuing Education Division, May 15-17.

19. Winograd, T. (1988) "A language/action perspective on the design of cooperative work." Human Computer Interaction, 3(1), 3-30. 